\title{
Towards annealing-stable molybdenum-oxide-based hole-selective contacts for silicon photovoltaics
}

 \\ Mathieu Boccard ${ }^{1 a}$, Jérémie Werner ${ }^{1}$, Jonas Geissbühler ${ }^{4}$, Philipp Löper ${ }^{1}$, Monica \\ Morales-Masis ${ }^{1}$, Lars Korte ${ }^{2}$, Stefaan De Wolf ${ }^{5}$, Christophe Ballif ${ }^{1}$ \\ ${ }^{1}$ École Polytechnique Fédérale de Lausanne (EPFL), Institute of Microengineering (IMT), Photovoltaics and Thin Film \\ Electronic Laboratory (PV-Lab), Rue de la Maladière 71b, 2002 Neuchâtel, Switzerland \\ ${ }^{2}$ Helmholtz-Zentrum Berlin for Materials and Energy (HZB), Institute of Silicon Photovoltaics, Kekuléstraße 5, \\ 12489 Berlin, Germany \\ ${ }^{3}$ National Institute of Advanced Industrial Science and Technology (AIST), 1-1-1 Umezono, Tsukuba, 305-8568, Japan \\ ${ }^{4}$ CSEM PV-center, Rue Jaquet-Droz 1, 2002 Neuchâtel, Switzerland \\ ${ }^{5}$ King Abdullah University of Science and Technology (KAUST), KAUST Solar Center (KSC), Thuwal 23955-6900, \\ Saudi Arabia
}

Molybdenum oxide $\left(\mathrm{MoO}_{\mathrm{X}}\right)$ combines a high work function with broadband optical transparency. Sandwiched between a hydrogenated intrinsic amorphous silicon passivation layer and a transparent conductive oxide, this material allows a highly efficient hole-selective front contact stack for crystalline silicon solar cells. However, hole extraction from the Si wafer and transport through this stack degrades upon annealing at $190^{\circ} \mathrm{C}$, which is needed to cure the screen-printed $\mathrm{Ag}$ metallization applied to typical Si solar cells. Here, we show that effusion of hydrogen from the adjacent layers is a likely cause for this degradation, highlighting the need for hydrogen-lean passivation layers when using such metal-oxidebased carrier-selective contacts. Pre-MoOX-deposition annealing of the passivating a-Si:H layer is shown to be a straightforward approach to manufacturing $\mathrm{MoO}_{\mathrm{X}}$-based devices with high fill factors using screen-printed metallization cured at $190{ }^{\circ} \mathrm{C}$. 
Passivating carrier-selective contacts offer a simple way to approach the theoretical efficiency limit of silicon (Si) solar cells without the need for expensive layer patterning, and they can offer superior performance under outdoor conditions $[1,2]$. In conventional Si homo-junction solar cells, carrier separation is ensured by highly doped regions within the $\mathrm{Si}$ wafer, and electrical contacts with low resistivity are obtained by applying metal electrodes directly onto the highly doped Si surfaces. Despite being extensively manufactured worldwide, such solar cells are limited in their efficiency potential due to defect-assisted and Auger recombination of charge carriers, respectively at the metal/silicon interface and in the doped Si regions. The use of passivating contacts-like the ones used in silicon heterojunction (SHJ) solar cells [3] — suppresses these recombination routes by separating the metal from the surface of the Si wafer and omitting heavy doping of the Si wafer. To reduce further optical losses in passivating contacts, the application of wide-bandgap materials like molybdenum-, tungsten-, titanium- or nickel-oxide $\left(\mathrm{MoO}_{\mathrm{X}}\right.$ [4-6], $\mathrm{WO}_{\mathrm{X}}$ [7, 8], $\mathrm{TiO}_{2}$ [9-11], $\mathrm{NiO}$ [10]), as well as lithium- or magnesium-fluoride ( $\mathrm{LiF}$ [12], $\mathrm{MgF}_{2}$ [13]) has received much attention in recent years. These materials feature a work function that is either higher than the ionization energy, or lower than the electron affinity of crystalline $\mathrm{Si}$ (c-Si). Therefore, when in contact with $\mathrm{Si}$ and depending on the band lineup and defect density of the interface, these materials may induce an electrical potential at the Si surface, which promotes the collection of either only holes or only electrons. As a specific example, the transition metal oxide $\mathrm{MoO}_{\mathrm{X}}(\mathrm{x} \approx 3)$ combines a wide optical bandgap energy of 2.8-3.1 eV [14] with a high work-function of 4.8 to $6.9 \mathrm{eV}[15,16]$; when deposited on Si surfaces, it may thus promote hole collection. Practically, conversion efficiencies up to $22.5 \%$ [5] were demonstrated for Si solar cells employing a $\mathrm{MoO}_{\mathrm{X}}(\mathrm{x} \approx 3)$ based hole-selective front emitter stack. The higher transparency of $\mathrm{MoO}_{\mathrm{X}}$ compared to p-type hydrogenated amorphous silicon layers (a-Si:H) led to $\sim 0.3 \mathrm{~mA} / \mathrm{cm}^{2}$ gain in photo current density compared to the reference SHJ cells [5]. To ensure passivation of the silicon surface, an additional a-Si:H buffer layer was inserted underneath this $\mathrm{MoO}_{\mathrm{X}}$ film, similar as in conventional SHJ technology. The $\mathrm{MoO}_{\mathrm{X}}$ film was capped with a transparent conductive oxide (TCO), either hydrogen doped indium oxide (IO:H) and indium tin oxide (ITO) stack [17] or simply ITO, to minimize resistive losses and maximize light in-coupling [18]. To finish the devices, a $\mathrm{Cu}$ front grid electrode [19 was formed by electroplating. This metallization technique notably does not require any thermal treatment above $125^{\circ} \mathrm{C}$. Despite its high work function, $\mathrm{MoO}_{\mathrm{X}}$ is an $\mathrm{n}$-type material [20]. As a consequence, efficient carrier extraction requires that photogenerated holes in the valence band of $\mathrm{c}-\mathrm{Si}$ recombine with electrons present in the $\mathrm{MoO}_{\mathrm{X}}$ conduction band; the latter electrons are injected from the degenerately n-doped TCO [4, 6]. Efficient charge-carrier transport through this contact stack depends on the thickness, defect density (for trap-assisted transport) and work function of $\mathrm{MoO}_{\mathrm{X}}[21,22]$, as well as on the line-up with the band edge energies of the surrounding layers.

Despite these promising results, industrial implementation of such contacts demands their compatibility with contemporary high-throughput grid metallization techniques, which currently consist mainly of screen-printing Ag paste, followed by a moderate-temperature cure at about $190{ }^{\circ} \mathrm{C}$. Unfortunately, applying this to our current implementation of $\mathrm{MoO}_{\mathrm{X}}$-based solar cells results in light current-voltage (JV) curves that are S-shaped near the opencircuit voltage $\left(\mathrm{V}_{\mathrm{OC}}\right)$, resulting in reduced fill factors $(\mathrm{FF})$ below 70\% [5]. We present here an experimental investigation by means of thermal desorption spectroscopy (TDS) and surface photovoltage spectroscopy (SPV) of the underlying degradation mechanisms leading to this FF degradation. These results hint at hydrogen effusion from the a-Si:H layer being the origin of the FF degradation, and we propose a solution similar to the approach described in [23] to mitigate this effect by annealing the a-Si:H-coated silicon wafers prior to $\mathrm{MoO}_{\mathrm{x}}$ deposition: This reduces the hydrogen content in the film, leading to reduced $\mathrm{H}$ effusion upon the final annealing step of the finished device.

For all experiments, $240 \mu \mathrm{m}$ thick, $\sim 3 \Omega \mathrm{cm}$ phosphorus-doped, float-zone (100) Si wafers were textured and cleaned. During solar cell fabrication at EPFL, a 5-nm-thick intrinsic, a-Si:H layer was applied by plasma enhanced chemical vapor deposition (PECVD) on the wafer's front side, and a $\sim 15 \mathrm{~nm}$ thick stack of intrinsic and n-type doped a-Si:H layers was deposited as the rear-electron collecting contact. On the front side, a $\sim 8 \mathrm{~nm}$ thick $\mathrm{MoO}_{\mathrm{X}}$ layer was thermally evaporated from $\mathrm{MoO}_{3}$ powder using a deposition rate of $0.05 \mathrm{~nm} / \mathrm{sec}$. The active solar cell areas were defined by sputter deposition of $\sim 70 \mathrm{~nm}$ thick ITO layers on the $\mathrm{MoO}_{\mathrm{X}}$. A full area ITO/Ag rear contact stack was deposited by sputtering and finally a front metal grid was prepared by Ag screen printing. Current-voltage (JV) characteristics were measured after stepwise curing of the $\mathrm{Ag}$ paste at $130{ }^{\circ} \mathrm{C}$ and $190{ }^{\circ} \mathrm{C}$. SPV measurements were performed at Helmholtz-Zentrum Berlin (HZB) on cells with $\mathrm{Cu}$-plated front contacts using a home-built setup with $905 \mathrm{~nm}$ laser excitation [24]. TDS was performed at the National Institute of Advanced Industrial Science and Technology (AIST) with a constant heating rate of $(20.0 \pm 0.1) \mathrm{K} / \mathrm{min}$ at a base pressure lower than $10^{-9} \mathrm{mbar}$.

Figure 1a shows the recorded TDS spectra of $\mathrm{H}_{2}$ from single a-Si:H and $\mathrm{MoO}_{\mathrm{X}}$ films as well as a-Si:H/MoOX and a-Si:H/MoOX $/ \mathrm{IO}: \mathrm{H}$ stacks. A single a-Si:H layer releases hydrogen $\left(\mathrm{H}_{2}\right)$ already at low temperatures around $100{ }^{\circ} \mathrm{C}$ with a desorption peak at $360{ }^{\circ} \mathrm{C}$, similarly to literature [25-28]. The presence of a $\mathrm{MoO}_{\mathrm{X}}$ layer on top of the a-Si:H leads to an earlier and also more pronounced release of $\mathrm{H}_{2}$ (at temperatures as low as $150{ }^{\circ} \mathrm{C}$ ) and shifts the effusion peak to $\sim 320^{\circ} \mathrm{C}$. A similar effect was obtained from identical measurements employing doped a-Si:H overlayers [28]. This effect was explained by reduction of the defect-formation energy when the Fermi-level inside the intrinsic a-Si:H is shifted closer to its band edges. Our experiments on $\mathrm{MoO}_{\mathrm{X}}$-based devices support well these earlier findings since a Fermi-level shift in the intrinsic a-Si:H closer to the valence band is also expected in this case, though the surface from which $\mathrm{H}$ effuses is different in our case. Next, we find that the $\mathrm{H}_{2}$ effusion peak of the a-Si:H/MoOX/IO:H stack is 
significantly lower in intensity, with an onset at increased temperatures $\left(\sim 230{ }^{\circ} \mathrm{C}\right.$ vs. $\sim 170{ }^{\circ} \mathrm{C}$ for the a-Si:H/MoO $\mathrm{M}$ stack). This suggests that $\mathrm{H}_{2}$ from the a-Si:H/MoOx stack is partially absorbed in the $\mathrm{IO}: \mathrm{H}$, and released in the form of $\mathrm{H}_{2} \mathrm{O}$, as clearly observed in Fig. 2b. The $\mathrm{H}_{2} \mathrm{O}$ desorption from IO:H (Figure 2b) is in good agreement with refs. [29,30]. The $\mathrm{H}_{2} \mathrm{O}$ effusion spectra of $\mathrm{c}-\mathrm{Si}$ with $\mathrm{MoO}_{\mathrm{X}}$ layers and a-Si.H/MoOx stacks have a sharp rise at temperatures close to $75{ }^{\circ} \mathrm{C}$ and indicate the thermal decomposition (reduction) of $\mathrm{MoO}_{\mathrm{X}}$. $(\mathrm{x} \sim 3)$, which is partly triggered by the presence of hydrogen [31]. The effect of the $\mathrm{H}_{2}$ effusion on the solar cell performance will be discussed below, based on SPV and IV measurements of completed solar cells.

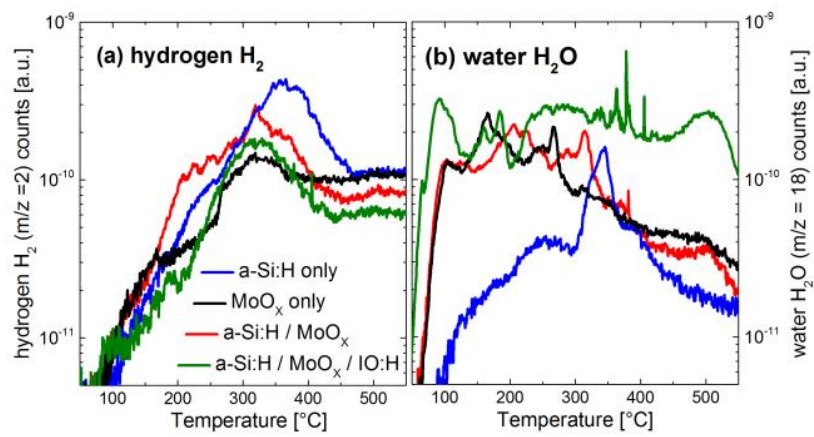

FIG. 1. $\mathrm{H}_{2}$ and $\mathrm{H}_{2} \mathrm{O}$ thermal desorption spectra of test structures consisting of a single layer of $\mathrm{MoO}_{\mathrm{X}}$ or a-Si:H on c-Si wafers or of stacks of $\mathrm{MoO}_{\mathrm{X}} / \mathrm{a}-\mathrm{Si}: \mathrm{H}$ or a-Si:H/ MoOx/IO:H on c-Si wafers. $\mathrm{H}_{2}$ effusion spectra: the existence of a $\mathrm{MoO}_{\mathrm{x}}$ layer on top of a-Si:H (red curve) leads to a shift of the main hydrogen effusion peak to lower temperatures as compared to a-Si:H alone (blue curve). $\mathrm{H}_{2} \mathrm{O}$ effusion spectra: the spectra show the release of $\mathrm{H}_{2} \mathrm{O}$ from the top IO:H film (green curve) and indicate the decomposition (reduction) of the $\mathrm{MoO}_{\mathrm{x}}$ films (red and black curves).

Figure 2a shows the changes in the MoOx[/a-Si:H]/c-Si band bending of our solar cells throughout annealing (temperatures of $100-250{ }^{\circ} \mathrm{C}$, each step $5 \mathrm{~min}$ ), as extracted from SPV measurements. Note that although the absolute value obtained with the setup used in this study are typically lower compared to the ones measured in other places [23], relative differences between samples can be discussed and correlate well to device properties [8]. The band bending of the $\mathrm{MoO}_{\mathrm{X}}$-based solar cell with the a-Si:H(i) buffer layer is significantly reduced by annealing, whereas the changes in the $\mathrm{MoO}_{\mathrm{X}}$ cell without the a-Si:H(i) layer are much smaller (especially between $170{ }^{\circ} \mathrm{C}$ and $210{ }^{\circ} \mathrm{C}$ ). The similar onset temperatures for band-bending reduction and $\mathrm{H}$ effusion from a-Si:H / $\mathrm{MoO}_{\mathrm{X}}$ stacks suggests that these effects are linked. We surmise that, similar to what has been found in tungsten oxide $\left(\mathrm{WO}_{\mathrm{X}}\right) / \mathrm{a}-\mathrm{Si}$ heterojunctions [8], hydrogen effuses from the a-Si:H layer, partially reducing $\mathrm{MoO}_{\mathrm{X}}$ and lowering its workfunction, leading to reduced c-Si band bending, thus degrading the hole-selectivity of our contact. This is reflected in the IV curves of corresponding devices at various annealing temperature, where a strong S-shape characteristic appears after annealing at $190^{\circ} \mathrm{C}$ for the $\mathrm{MoO}_{\mathrm{X}}$ based device incorporating an a-Si:H layer but not for the one not incorporating this a-Si:H layer. Also, in case the degradation of workfunction is accompanied with a lowering of the electron affinity and ionization potential, the energetic gap between the a-Si:H valence band and the TCO conduction band is increased, as sketched in Figure $2 b$, deteriorating transport by reducing the probability of (trap-assisted) tunneling within the MoOX layer. Notably, reduction of the oxidation state of the $\mathrm{MoO}_{\mathrm{X}}$ layer - and possibly hydrogenation - can- affect the workfunction by moving the Fermi-level only without affecting the band structure, but can also reduce the workfunction and activation energy and ionization potential similarly, thus shifting the band structure towards the vacuum level energy [15,32]. Both effects have been reproduced in Fig. $2 \mathrm{~b}$ to keep it general. A reduced band bending close to the Si surface also decreases the potential drop in the a-Si:H layer. In turn, the thermionic field emission over the band offset at the a$\mathrm{Si}: \mathrm{H} / \mathrm{c}-\mathrm{Si}$ interface is reduced, eventually leading to a transport barrier for holes, resulting in S-shaped JV curves as reported in our earlier work [5]. The dominant transport limitation at stake in our device is unclear-the role of eventual trap states and dipoles possibly bringing additional contributions, though the origin being a drop of workfunction through $\mathrm{H}$-enhanced reduction is a likely cause in all three cases which correlates well with effusion measurement. As a consequence, buffer layers which do not effuse hydrogen upon annealing up to $200{ }^{\circ} \mathrm{C}$ are desirable to obtain annealing-stable $\mathrm{MoO}_{\mathrm{X}}$-based hole-selective contacts. The next section discusses how annealing the a-Si:H passivating layers prior to $\mathrm{MoO}_{\mathrm{X}}$ deposition could lead to such $\mathrm{H}$-effusion-free buffer layer, as we observe good passivation and efficient carrier transport when using such layer-even after annealing the finished device at $190{ }^{\circ} \mathrm{C}$. 

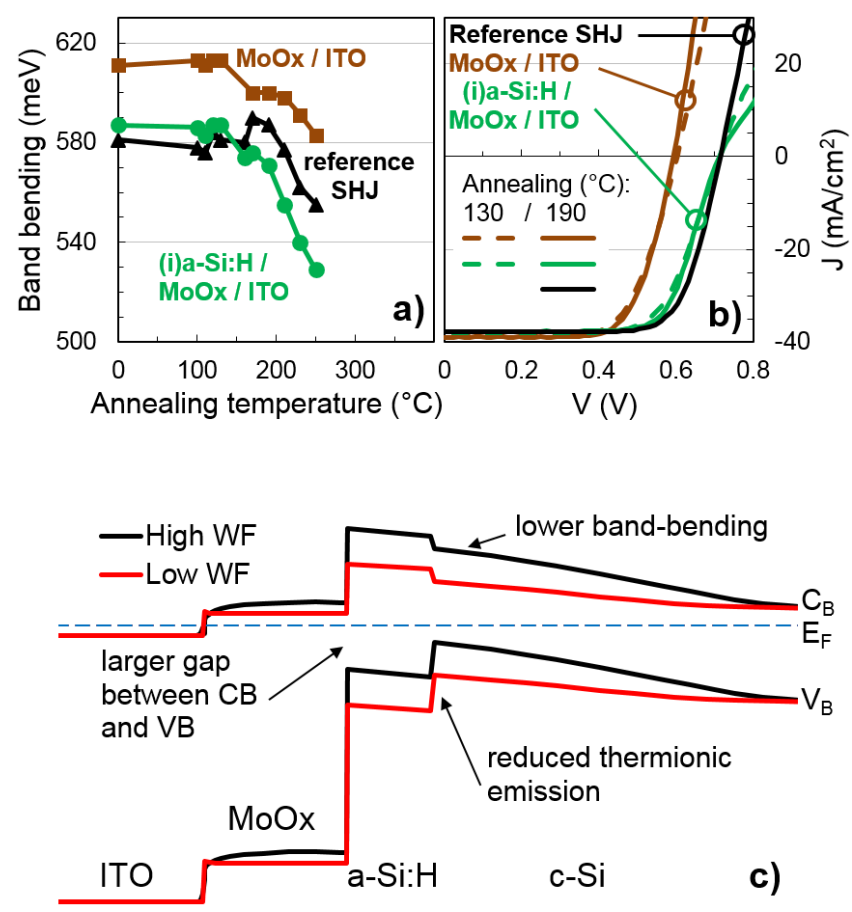

Figure 2. (a) Band bending extracted from SPV measurements on three solar cells with $\mathrm{MoO}_{\mathrm{X}}$ based hole-selective front contacts and one SHJ reference cell. The cell without the a-Si:H buffer layer has the strongest band bending and is less affected by stepwise annealing. (b) Current-voltace characteristics of corresponding devices after annealing at $130{ }^{\circ} \mathrm{C}$ and $190{ }^{\circ} \mathrm{C}$. (c) Qualitative sketch of the energy band diagram of a MoOx-based front contact. The effect of a reduced MoOx work function on the $\mathrm{MoOx} / \mathrm{a}-\mathrm{Si}(\mathrm{i}) / \mathrm{c}-\mathrm{Si}$ (inverted n-type surface layer) stack is illustrated ( $\mathrm{VB}=$ valence band, $\mathrm{E}_{\mathrm{F}}=$ Fermi-energy, $\mathrm{CB}=$ conduction band).

Fig. 3 shows the electrical properties of solar cells incorporating a pre- $\mathrm{MoO}_{\mathrm{X}}$-deposition annealing step at a temperature of $200{ }^{\circ} \mathrm{C}$ to $300{ }^{\circ} \mathrm{C}$. The parameters are displayed after two different temperatures of annealing of the finished device, used to cure the screen printed $\mathrm{Ag}$ contacts: $130{ }^{\circ} \mathrm{C}$ and $190{ }^{\circ} \mathrm{C}$. The $\mathrm{V}_{\mathrm{OC}}$ is degraded by the preMoOx-deposition annealing, with a stronger drop when increasing the pre-annealing temperature. This can be attributed to dehydrogenation and thus passivation degradation of the a-Si:H passivation layer, both on the holecollecting side and electron-collecting-side for highest temperatures [28,33]. Notably, a degradation is seen after metal curing at $190{ }^{\circ} \mathrm{C}$ for devices exposed to a pre-MoOx-deposition annealing at a temperature below $250{ }^{\circ} \mathrm{C}$, whereas an improvement is observed for temperatures higher than $250{ }^{\circ} \mathrm{C}$. This can possibly be attributed to the recovery of sputter-induced damage, occurring for all samples but specifically visible for the higher pre-MoOx-deposition annealing temperatures: for the low pre-MoOx-deposition annealing temperatures, this recovery is overcompensated by a drop due to the loss of selectivity of the MoOx-based device. Turning to FF, an optimum pre-annealing temperature of $250^{\circ} \mathrm{C}$ is seen both prior to and after final curing at $190{ }^{\circ} \mathrm{C}$. The drop for too high pre-MoOx-deposition annealing temperatures can be attributed to the passivation loss due to too strong de-hydrogenation, whereas the drop for too low temperatures can be attributed to the selectivity drop, specially seen after curing at $190{ }^{\circ} \mathrm{C}$. A $4 \% \mathrm{FF}$ gain is observed upon pre-annealing at $250{ }^{\circ} \mathrm{C}$ compared to pre-annealing at $200{ }^{\circ} \mathrm{C}$ only (which gives similar results to no pre-annealing, not shown), clearly evidencing the effectiveness of the approach. No trend is seen for the $\mathrm{J}_{\mathrm{SC}}$ within the accuracy of the measurement, and finally the efficiency follows mostly the FF trend with an optimum at a pre-annealing temperature of $250^{\circ} \mathrm{C}$. Using this pre-annealing temperature, we fabricated solar cells with $\mathrm{MoO}$-based hole-selective contacts reaching fill factor values of $76 \%$ and an efficiency of $20.8 \%$ after curing of the front Ag metal grid at 190 ${ }^{\circ} \mathrm{C}$. Notably, the corresponding JV-curve does not exhibit an S-shape around $\mathrm{V}_{\mathrm{OC}}$ and the determined FF is close to the value achieved with sister samples featuring our baseline a-Si:H(i)/a-Si:H(p) front hole-selective contact. The slightly reduced $\mathrm{V}_{\mathrm{OC}}$ compared to values obtained with standard a-Si:H(p) layers can be attributed to a slightly degraded a$\mathrm{Si} H \mathrm{H}$ passivation from pre-annealing, which may be resolved by designing passivation layers more resilient to thermal annealing at $250{ }^{\circ} \mathrm{C}$, or releasing less hydrogen at this temperature, such as a-SiC $\mathrm{X}_{\mathrm{X}}: \mathrm{H}$ films [33]. 


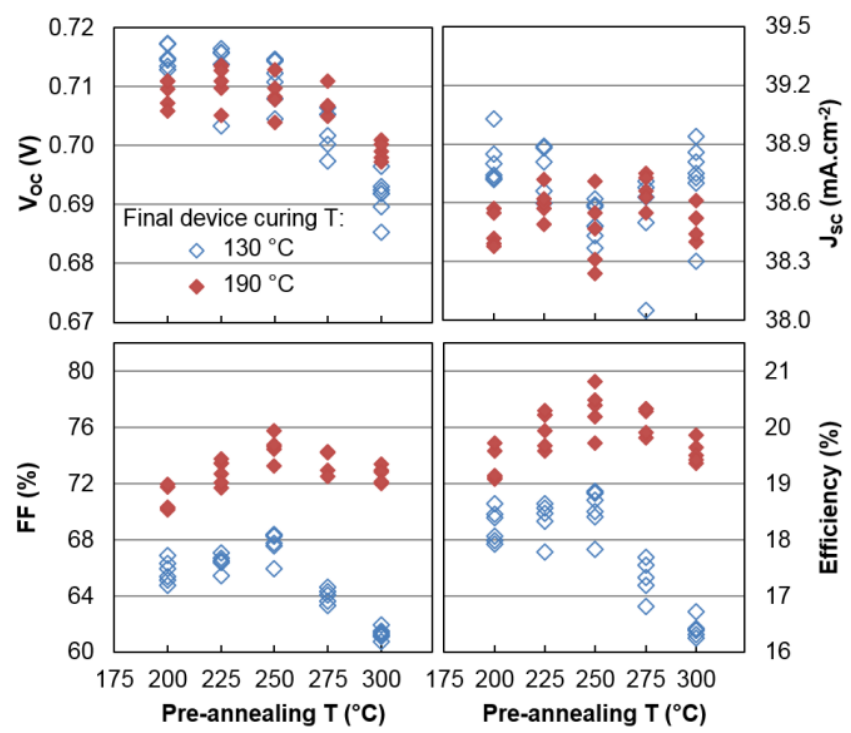

FIG. 3. JV parameters of MoOx-based solar cells as a function of the temperature of pre-MoOxdeposition annealing of the a-Si:H layers. JV parameters are displayed after curing the finished device at $130{ }^{\circ} \mathrm{C}$ and at $190{ }^{\circ} \mathrm{C}$.

To conclude, our experiments show that silicon solar cells with a-Si:H/MoOX/TCO hole-selective contact stacks suffer from severe fill factor degradation and S-shaped JV curves when thermally annealed at $190{ }^{\circ} \mathrm{C}$. Though the presented results are not sufficient to fully explain this degradation, we show in this study that it can be mitigated by reducing the amount of hydrogen in the adjacent layers. TDS measurements provide evidence that a $\mathrm{MoO}_{\mathrm{x}}$ overlayer shifts hydrogen effusion from a-Si:H(i) layers towards lower temperatures, confirming the theory of Fermi-leveldependent hydrogen bond breaking. SPV measurements showed that insertion of the a-Si:H(i) passivation layer and annealing at $190^{\circ} \mathrm{C}$ leads to a lower band bending and indicate that the work function of $\mathrm{MoO}_{\mathrm{X}}$ decreases with increasing annealing temperature. In summary, our observations hint at a transport barrier induced by hydrogen release from the a-Si:H layer, and we suggest a pre- $\mathrm{MoO}_{\mathrm{X}}$-deposition annealing step of the a-Si:H layer to reduce its hydrogen content and allow high FF to be obtained. An optimum temperature of $250{ }^{\circ} \mathrm{C}$ is shown for such treatments, allowing up to $20.8 \%$-efficient $\mathrm{MoO}_{\mathrm{x}}$-based solar cells, using a Ag-paste curing temperature of $190{ }^{\circ} \mathrm{C}$. Yet, although such thermal treatment allows significant improvement compared to a non-annealed device, the efficiency of $\mathrm{MoO}_{\mathrm{x}}$-based devices obtained with this approach is still limited by a passivation/transport trade-off, highlighting the need for an alternate passivation strategy to fully exploit the potential of $\mathrm{MoO}_{\mathrm{x}}$ as a hole-selective contact.

\section{ACKNOWLEDGMENTS}

The authors would like to thank Raphaël Monnard and Guillaume Charitat from EPFL and Nicolas Badel, Silvia Martin de Nicolas and Fabien Debrot from CSEM for work performed in the context of this publication. Furthermore, we thank Davide Sacchetto and Sylvain Nicolay from CSEM, and Andres Cuevas from ANU for discussions, Virginia Unkefer from KAUST for manuscript editing. S. Essig held a Marie Skłodowska-Curie Individual Fellowship from the European Research Council (ERC) under the European Union's Horizon 2020 research and innovation programme (grant agreement No: 706744, action acronym: COLIBRI). Part of this work was funded by the European Union's Horizon 2020 research and innovation programme under Grant Agreements no. 727529 (project DISC), and by the Swiss National Science Foundation via the NRP70 "Energy Turnaround" project "PV2050".

\section{REFERENCES}

[1] C. Battaglia, A. Cuevas, and S. De Wolf, "High-efficiency crystalline silicon solar cells: status and perspectives," Energy \& Environmental Science, vol. 9, pp. 1552-1576, 2016.

[2] J. Haschke, J. P. Seif, Y. Riesen, A. Tomasi, J. Cattin, L. Tous, P. Choulat, M. Aleman, E. Cornagliotti, A. Uruena, et al., "The impact of silicon solar cell architecture and cell interconnection on energy yield in hot \& sunny climates," Energy \& Environmental Science, 2017.

[3] S. De Wolf, A. Descoeudres, C. Holman Zachary, and C. Ballif, "High-efficiency Silicon Heterojunction Solar Cells: A Review," in green vol. 2, ed, 2012, p. 7.

[4] C. Battaglia, S. M. de Nicolás, S. De Wolf, X. Yin, M. Zheng, C. Ballif, and A. Javey, "Silicon heterojunction solar cell with passivated hole selective MoOx contact," Applied Physics Letters, vol. 104, p. 113902, 2014. 
[5] J. Geissbühler, J. Werner, S. Martin de Nicolas, L. Barraud, A. Hessler-Wyser, M. Despeisse, S. Nicolay, A. Tomasi, B. Niesen, S. De Wolf, et al., "22.5\% efficient silicon heterojunction solar cell with molybdenum oxide hole collector," Applied Physics Letters, vol. 107, p. 081601, 2015.

[6] J. Ziegler, M. Mews, K. Kaufmann, T. Schneider, A. N. Sprafke, L. Korte, and R. B. Wehrspohn "Plasmaenhanced atomic-layer-deposited MoO x emitters for silicon heterojunction solar cells," Applied Physics A, vol. 120, pp. 811-816, 2015.

[7] M. Bivour, J. Temmler, H. Steinkemper, and M. Hermle, "Molybdenum and tungsten oxide: High work function wide band gap contact materials for hole selective contacts of silicon solar cells," Solar Energy Materials and Solar Cells, vol. 142, pp. 34-41, 11// 2015.

[8] M. Mews, L. Korte, and B. Rech, "Oxygen vacancies in tungsten oxide and their influence on tungsten oxide/silicon heterojunction solar cells," Solar Energy Materials and Solar Cells, vol. 158, pp. 77-83, 2016.

[9] S. Avasthi, W. E. McClain, G. Man, A. Kahn, J. Schwartz, and J. C. Sturm, "Hole-blocking titaniumoxide/silicon heterojunction and its application to photovoltaics," Applied Physics Letters, vol. 102, p. 203901, 2013.

[10] H. Imran, T. M. Abdolkader, and N. Z. Butt, "Carrier-Selective NiO/Si and TiO2 Contacts for Silicon Heterojunction Solar Cells," IEEE Transactions on Electron Devices, vol. 63, pp. 3584-3590, 2016.

[11] X. Yang, Q. Bi, H. Ali, K. Davis, W. V. Schoenfeld, and K. Weber, "High-Performance TiO2-Based ElectronSelective Contacts for Crystalline Silicon Solar Cells," Advanced Materials, vol. 28, pp. 5891-5897, 2016.

[12] J. Bullock, M. Hettick, J. Geissbühler, A. J. Ong, T. Allen, Carolin M. Sutter-Fella, T. Chen, H. Ota, E. W. Schaler, S. De Wolf, et al., "Efficient silicon solar cells with dopant-free asymmetric heterocontacts," Nature Energy, vol. 1, p. 15031, 01/25/online 2016.

[13] Y. Wan, C. Samundsett, J. Bullock, T. Allen, M. Hettick, D. Yan, P. Zheng, X. Zhang, J. Cui, J. McKeon, et al., "Magnesium Fluoride Electron-Selective Contacts for Crystalline Silicon Solar Cells," ACS Applied Materials \& Interfaces, vol. 8, pp. 14671-14677, 2016/06/15 2016.

[14] "Non-Tetrahedrally Bonded Binary Compounds II · MoO3: energy gap: Datasheet from Landolt-Börnstein Group III Condensed Matter • Volume 41D: "Non-Tetrahedrally Bonded Binary Compounds II" in SpringerMaterials (http://dx.doi.org/10.1007/10681735_662)," O. Madelung, U. Rössler, and M. Schulz, Eds., ed: Springer-Verlag Berlin Heidelberg.

[15] M. Vasilopoulou, A. M. Douvas, D. G. Georgiadou, L. C. Palilis, S. Kennou, L. Sygellou, A. Soultati, I. Kostis, G. Papadimitropoulos, D. Davazoglou, et al., "The Influence of Hydrogenation and Oxygen Vacancies on Molybdenum Oxides Work Function and Gap States for Application in Organic Optoelectronics," Journal of the American Chemical Society, vol. 134, pp. 16178-16187, 2012/10/03 2012.

[16] J. Meyer, S. Hamwi, M. Kröger, W. Kowalsky, T. Riedl, and A. Kahn, "Transition Metal Oxides for Organic Electronics: Energetics, Device Physics and Applications," Advanced Materials, vol. 24, pp. 5408-5427, 2012.

[17] L. Barraud, Z. C. Holman, N. Badel, P. Reiss, A. Descoeudres, C. Battaglia, S. De Wolf, and C. Ballif, "Hydrogen-doped indium oxide/indium tin oxide bilayers for high-efficiency silicon heterojunction solar cells," Solar Energy Materials and Solar Cells, vol. 115, pp. 151-156, 8// 2013.

[18] M. Morales-Masis, S. De Wolf, R. Woods-Robinson, J. W. Ager, and C. Ballif, "Transparent Electrodes for Efficient Optoelectronics," Advanced Electronic Materials, vol. 3, pp. 1600529-n/a, 2017.

[19] J. Geissbühler, S. D. Wolf, A. Faes, N. Badel, Q. Jeangros, A. Tomasi, L. Barraud, A. Descoeudres, M. Despeisse, and C. Ballif, "Silicon Heterojunction Solar Cells With Copper-Plated Grid Electrodes: Status and Comparison With Silver Thick-Film Techniques," IEEE Journal of Photovoltaics, vol. 4, pp. 1055-1062, 2014.

[20] M. Kröger, S. Hamwi, J. Meyer, T. Riedl, W. Kowalsky, and A. Kahn, "Role of the deep-lying electronic states of MoO3 in the enhancement of hole-injection in organic thin films," Applied Physics Letters, vol. 95, p. 123301, 2009.

[21] R. A. Vijayan, S. Essig, S. D. Wolf, B. G. Ramanathan, P. Löper, C. Ballif, and M. Varadharajaperumal, "Hole-Collection Mechanism in Passivating Metal Oxide Contacts for Si Solar Cells: Insights from Numerical Simulation," IEEE Journal of Photovoltaics, under review March 2017.

[22] M. Bivour, B. Macco, J. Temmler, W. M. M. Kessels, and M. Hermle, "Atomic Layer Deposited Molybdenum Oxide for the Hole-selective Contact of Silicon Solar Cells," Energy Procedia, vol. 92, pp. 443-449, 8// 2016.

[23] Neusel, Lisa, Martin Bivour, and Martin Hermle. "Selectivity issues of MoO x based hole contacts." Energy Procedia 124 (2017): 425-434.

[24] K. Heilig, "Determination of surface properties by means of large signal photovoltage pulses and the influence of trapping," Surface Science, vol. 44, pp. 421-437, 1974/08/01 1974.

[25] R. A. Street, C. C. Tsai, J. Kakalios, and W. B. Jackson, "Hydrogen diffusion in amorphous silicon," Philosophical Magazine Part B, vol. 56, pp. 305-320, 1987/09/01 1987.

[26] W. Beyer, "Hydrogen incorporation, stability, and release effects in thin film silicon," physica status solidi (a), vol. 213, pp. 1661-1674, 2016.

[27] W. Beyer, J. Herion, and H. Wagner, "Fermi energy dependence of surface desorption and diffusion of hydrogen in a-Si:H," Journal of Non-Crystalline Solids, vol. 114, pp. 217-219, 1989/12/01 1989. 
[28] S. De Wolf and M. Kondo, "Nature of doped a-Si:H/c-Si interface recombination," Journal of Applied Physics, vol. 105, p. 103707, 2009.

[29] T. Koida, M. Kondo, K. Tsutsumi, A. Sakaguchi, M. Suzuki, and H. Fujiwara, "Hydrogen-doped In2O3 transparent conducting oxide films prepared by solid-phase crystallization method," Journal of Applied Physics, vol. 107, p. 033514, 2010.

[30] H. Wardenga, M. Frischbier, M. Morales-Masis, and A. Klein, "In Situ Hall Effect Monitoring of Vacuum Annealing of $\mathrm{In}_{2} \mathrm{O}_{3}: \mathrm{H}$ Thin Films," Materials, vol. 8, p. 561, 2015.

[31] J. Dang, G.-H. Zhang, K.-C. Chou, R. G. Reddy, Y. He, and Y. Sun, "Kinetics and mechanism of hydrogen reduction of MoO3 to MoO2," International Journal of Refractory Metals and Hard Materials, vol. 41, pp. 216-223, 2013.

[32] Mark T. sGreiner, Lily Chai, Michael G. Helander, Wing-Man Tang, and Zheng-Hong Lu. "Transition metal oxide work functions: the influence of cation oxidation state and oxygen vacancies." Advanced Functional Materials 22, no. 21 (2012): 4557-4568.

[33] M. Boccard and Z. C. Holman, "Amorphous silicon carbide passivating layers for crystalline-silicon-based heterojunction solar cells," Journal of Applied Physics, vol. 118, p. 065704, 2015. 